\title{
Model Perangkingan Proyek Kontruksi pada Asosiasi Kontraktor Menggunakan Fuzzy AHP
}

\author{
Denny Jean Cross Sihombing ${ }^{1}$, Albertus Joko Santoso ${ }^{2}$, Sapty Rahayu ${ }^{3}$ \\ 1,2,3 Magister Teknik Informatika, Universitas Atma Jaya Yogyakarta \\ Email: ${ }^{1}$ dennyjcsihombing@gmail.com, ${ }^{2}$ albjoko@mail.uajy.ac.id, ${ }^{3}$ saptyrahayu@gmail.com
}

\begin{abstract}
Abstrak
Pemilihan proyek potensial dari paket lelang konstruksi yang ditawarkan merupakan permasalahan yang kompleks pada asosiasi kontraktor. Paket lelang yang ditawarkan oleh pemerintah melalui Kementerian Pekerjaan Umum (PU) untuk wilayah Sumatera Utara tahun 2013 terdapat 96 paket, tahun 2014 terdapat 69 paket. Dari banyaknya paket yang ditawarkan, masing-masing paket memiliki beberapa kriteria sebagai persyaratan, salah satunya adalah pengalaman perusahaan. Artikel ini fokus pada perangkingan proyek berdasarkan evaluasi proyek yang sudah dikerjakan sebelumnya. Keberhasilan suatu proyek ditentukan oleh beberapa kriteria, maka pendekatan yang digunakan Multi Criteria Decision Analysis (MCDA) dengan metode Fuzzy Analytic Hierarchy Process (FAHP), data diperoleh dari Asosiasi Kontraktor Air Indonesia (AKAINDO) Sumatera Utara. Hasilnya adalah rekomendasi proyek potensial berdasarkan skor tertinggi, yaitu sub-bidang perpipaan.
\end{abstract}

Kata Kunci: Multi criteria decision analysis, Fuzzy AHP, Perangkingan proyek kontruksi

\section{PENDAHULUAN}

Pemilihan proyek merupakan permasalahan kompleks pada Asosiasi kontraktor. Pada tahun 2013, paket lelang yang ditawarkan oleh pemerintah melalui Kementerian Pekerjaan Umum (PU) terdapat 96 paket, tahun 2014 terdapat 69 paket untuk wilayah Sumatera Utara. Dari banyaknya paket yang ditawarkan masing-masing paket memiki beberapa kriteria sebagai persyaratannya harus dipenuhi oleh peserta lelang. Banyaknya paket lelang membuka peluang pada asosiasi kontraktor, namun pemilihan proyek potensial ditawarkan menjadi tantangan dari asosiasi kontraktor.

Pada Asosiasi Kontraktor Air Indonesia (AKAINDO) Sumatera Utara, setiap anggota yang terdaftar pada asosiasi mengajukan permohonan pada ketua asosiasi. Ketua asosiasi mengevaluasi sumber daya (resource) dan persyaratan yang harus dipenuhi perusahaan. Banyaknya perusahaan yang tergabung dalam asosiasi menjadi permasalahan tersendiri dalam penyesuaian kriteria yang dipersyaratkan oleh panitia lelang dan kapabilitas perusahaan. Saat ini, pemilihan perusahaan oleh ketua asosiasi dilakukan secara manual dengan memperhatikan dokumen perusahaan.

Selanjutnya akan difokus pada perangkingan proyek berdasarkan evaluasi proyek yang sudah dikerjakan sebelumnya untuk mengidentifikasi proyek potensial yang akan diikuti proses lelangnya. Beberapa faktor penentu keberhasilan proyek konstruksi yaitu jangka waku pengerjaan, perencanaan, relasi antara konsultan dan perusahaan, performa, pengadaan, cara pembayaran, aliran dana, ansuransi, jaminan bank, penyelesaian proyek, penggunaan teknologi, profit, pengalaman perusahaan, nama baik, sistem manajemen perusahaan, kualitas, sumber daya manusia, kebijakan pemerintah, 
kondisi pasar, dan situasi politik [1]. Terdapat lebih dari satu kriteria yang digunakan dalam evaluasi proyek maka pendekatan yang digunakan adalah Multi Criteria Decision Analysis (MCDA), pada perangkingan proyek menggunakan metode Analytic Hierarchy Process (AHP). Permasalahan pemilihan proyek sangat kompleks, terdapat data kualitatif dalam evaluasi perusahaan maka pendekatan yang digunakan Fuzzy AHP.

Prosedur pengajuan tender terdiri dari tiga tahap yaitu project selection, markup decision dan preparation of biddings documents [2]. Pada tahapan pemilihan proyek, diperlukan analisa yang baik. Alasan perlunya analisa yang baik dalam pemilihan proyek yaitu terkait dengan sumber daya (resource), biaya persiapan pelaksanaan proyek dan reputasi perusahaan, aktifitas ini merupakan bagian dari manajemen proyek. Manajemen proyek merupakan suatu proses dari perencanaan, pengaturan, dan pengendalian dari suatu proyek dengan memanfaatkan sumber daya seoptimal mungkin untuk mencapai sasaran yang telah ditentukan. Fungsi dasar manajemen proyek terdiri dari pengelolaan lingkup pekerjaan, waktu, biaya, dan mutu.

Industri konstruksi menjadi sorotan di berbagai negara, terkait dengan sumbangsih yang besar pada berbagai sektor, terutama ekonomi [3]. Penelitian terkait dengan industri konstruksi, diantaranya kelanjutan material dalam pekerjaan konstruksi [4], [5], evaluasi investasi proyek [6], evaluasi kinerja kontraktor [7], risk management [8], [9] dan pemilihan supplier [10].

Multi Criteria Decision Analysis (MCDA) merupakan suatu metode pengambilan keputusan untuk menetapkan alternatif terbaik dari sejumlah alternatif berdasarkan beberapa kriteria tertentu. Kriteria dalam MCDA berupa ukuran-ukuran, aturan-aturan atau standar yang digunakan dalam pengambilan keputusan. Salah satu metode dalam MCDA adalah Fuzzy AHP. Beberapa penelitian yang menggunakan pendekatan Fuzzy AHP [11] melakukan penelitian pada bidang konstruksi, fokusnya pada planning dan budgeting. Penelitian [12] dalam pemilihan supplier pada industri retail antara lain problem structuring, assessment of local priorities dan calculation of global priorities (studi kasus pada bidang airline retail). Fuzzy AHP digunakan karena terdapat banyak data kualitatif dan kriteria dalam penentuan supplier. Dengan menggunakan FAHP dikategorikan supplier prioritas, penelitian lain adalah untuk mengembangkan kerangka pendukung keputusan multi-kriteria sistem pasokan energi terbarukan (studi kasus di negara Turki) [13].

\section{METODE}

\subsection{Metode yang Digunakan}

Data diperoleh dari Asosiasi Kontraktor Air Indonesia (AKAINDO) Sumatera Utara. Tahapan dalam penelitan ini adalah:

1) Membuat struktur hirarki evaluasi proyek.

Pada tahapan ini akan diformulasikan permasalahan dalam evaluasi proyek dan digambarkan dalam struktur hirarki.

2) Analisis kriteria.

Tahapan ini akan dilakukan analisis kriteria dalam evaluasi proyek.

3) Melakukan evaluasi proyek dengan pendekatan Fuzzy AHP. 
Tahapan ini dilakukan evaluasi proyek, evaluasi proyek berdasarkan keberhasilan proyek sebelumnya. Selanjutnya akan dilakukan evaluasi terhadap 3 sub-bidang proyek konstruksi.

4) Rekomendasi proyek.

Tahapan ini adalah memberikan rekomendasi proyek potensial berdasarkan evaluasi yang dilakukan pada tahap sebelumnya.

Urutan tahapan tersebut dapat ditunjukkan pada Gambar 1.

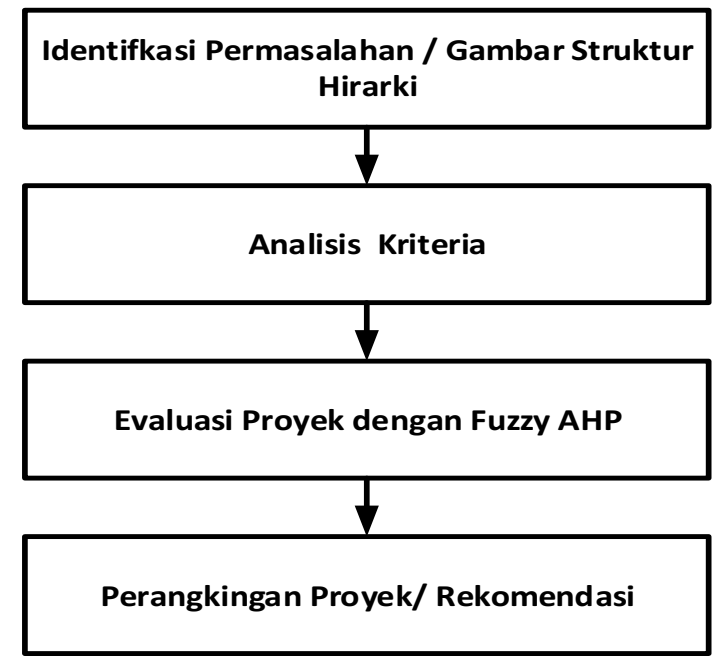

Gambar 1. Metode Penelitan

\subsection{Fuzzy $A H P$}

Langkah-langkah penyelesaian FAHP [14], [15], sebagai berikut:

1) Membuat struktur hirarki masalah dan membuat matriks perbandingan berpasangan menggunakan skala TFN.

2) Menentukan nilai sintesis fuzzy (Si) prioritas dengan rumus:

$$
S_{i}=\sum_{j=1}^{m} M_{i}^{j} \times \frac{1}{\sum_{i=1}^{n} \Sigma_{j=1}^{m} M_{i}^{j}}
$$

Dimana

$$
\sum_{j=1}^{m} M_{i}^{j}=\sum_{j=1}^{m} l j, \sum_{j=1}^{m} m j, \sum_{j=1}^{m} u j
$$

Sedangkan

$$
\frac{1}{\sum_{j=1}^{n} \sum_{j=1}^{m} M_{i}^{j}}=\frac{1}{\sum_{i=1}^{n} u i, \sum_{i=1}^{n} m i, \sum_{i=1}^{n} l i}
$$


3) Menentukan nilai vektor (V) dan nilai ordinat defuzzifikasi (d') dengan menggunakan aturan seperti pada persamaan (4).

$$
\begin{aligned}
& V=(M 2 \geq M 1)= \\
& \left\{\begin{array}{cc}
1 & \text { if } m_{2} \geq m_{1} \\
0 & \text { if } l_{1} \geq u_{2} \\
\frac{l_{1}-u_{2}}{\left(m_{2}-u_{2}\right)-\left(m_{1}-l_{1}\right)} & \text {, lainnya }
\end{array}\right\}
\end{aligned}
$$

4) Jika hasil nilai fuzzy lebih besar dari $\mathrm{k}$, Mi (i=1,2,..k) maka nilai vektor dapat didefinisikan sebagai berikut:

$$
\begin{aligned}
& V\left(M \geq M_{1}, M_{2}, \ldots, M_{k}\right)=V(M \geq \\
& \left.M_{1}\right) \operatorname{dan} V=\left(M \geq M_{2}\right) \operatorname{dan} \ldots V(M \geq \\
& \left.M_{k}\right)=\min V\left(M \geq M_{i}\right)
\end{aligned}
$$

Asumsikan bahwa,

$$
d^{\prime}\left(A_{i}\right)=\min V\left(S_{i} \geq S_{k}\right)
$$

untuk $\mathrm{k}=1,2, . . \mathrm{n} ; \mathrm{k} \neq \mathrm{i}$, maka diperoleh nilai bobot vektor

$$
W^{\prime}=\left(d^{\prime}\left(A_{1}\right), d^{\prime}\left(A_{2}\right), \ldots, d^{\prime}\left(A_{n}\right)\right)^{\prime}
$$

dimana $\mathrm{Ai}=1,2, . . \mathrm{n}$ adalah $\mathrm{n}$ elemen keputusan.

5) Normalisasi nilai bobot fuzzy (W)

$$
W=\left(d\left(A_{1}\right), d\left(A_{2}\right), \ldots, d\left(A_{n}\right)\right)^{T}
$$

dimana $\mathrm{W}$ adalah bilangan non fuzzy.

Fungsi keanggotaan skala TFN dalam variabel linguistik terdapat pada Tabel 1.

Tabel 1. Fungsi keanggotaan skala TFN dalam variabel linguistik

\begin{tabular}{ccc}
\hline Skala AHP & Variabel Lingustik & Fuzzy Triangular \\
\hline $\mathbf{1}$ & Sama Penting (SP) & $(1,1,1)$ \\
$\mathbf{3}$ & Hampir Cukup Penting (HCP) & $(2,3,4)$ \\
$\mathbf{5}$ & Cukup Penting (CP) & $(4,5,6)$ \\
$\mathbf{7}$ & Penting & $(6,7,8)$ \\
$\mathbf{9}$ & Sangat Penting (SP) & $(9,9,9)$ \\
$\mathbf{2}$ & nilai Intermittent antara 2 skala yang & $(1,2,3)$ \\
$\mathbf{4}$ & berdekatan & $(3,4,5)$ \\
$\mathbf{6}$ & & $(5,6,7)$ \\
$\mathbf{8}$ & & $(7,8,9)$ \\
\hline
\end{tabular}

\section{HASIL DAN PEMBAHASAN}

Pada Asosiasi kontraktor Air Indonesia (AKAINDO) Sumatera Utara terdapat 137 perusahaan konstruksi yang bergabung, dengan rincian: grade 2 (dua) 52 perusahaan, grade 3 (tiga) 37 perusahaan, grade 4 (empat) 36 perusahaan, grade 5 (lima) 11 perusahaan dan grade 6 (enam) 1 perusahaan. Perangkingan proyek dilakukan berdasarkan sub-bidang proyek konstruksi. 
Kriteria yang digunakan adalah:
1) Waktu.
2) Kualitas.
3) Biaya.
4) Kinerja tim.
5) Lingkungan.

Sedangkan sub-bidang konstruksi yang menjadi alternatif yaitu:

1) A1: Sub Bidang Irigasi.

2) A2: Sub Bidang Pengolahan Air Limbah.

3) A3: Sub Bidang Perpipaan.

Skema hirarki evaluasi proyek di atas dapat ditunjukkan dalam Gambar 2.

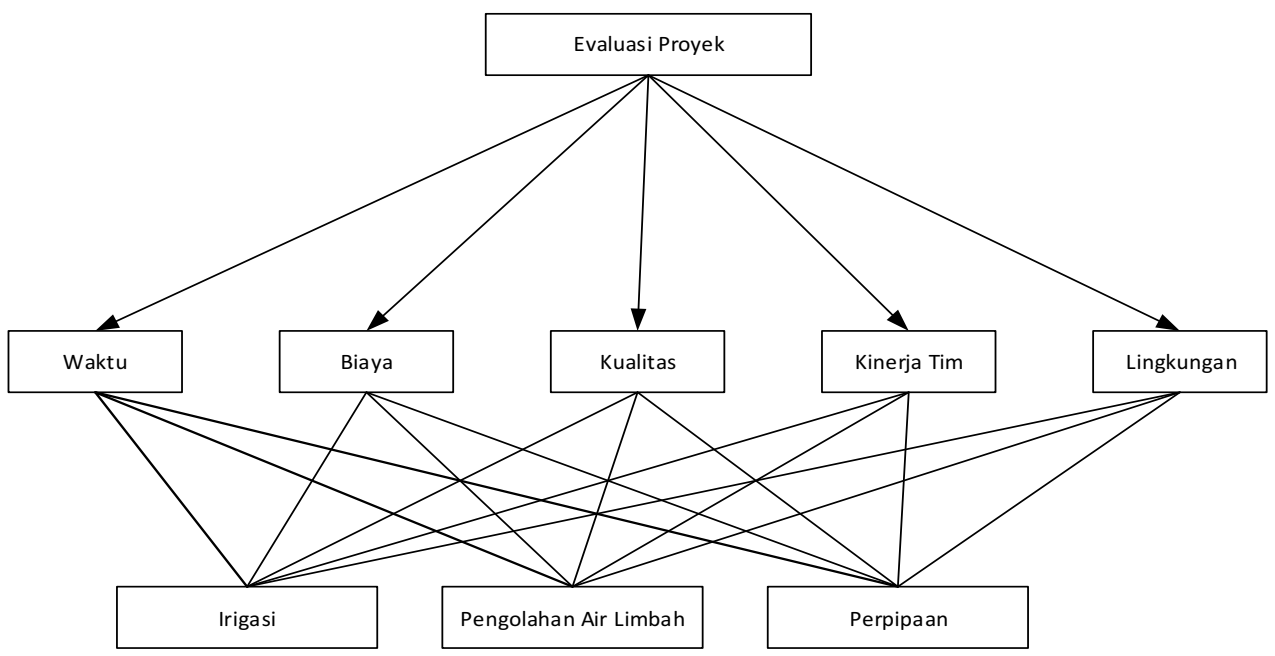

Gambar 2. Hirarki evaluasi proyek

Berikut tahapan evaluasi proyek:

1. Pembobotan kriteria.

Tahapan dalam pembobotan kriteria adalah dengan membuat matriks comparison (Tabel 2). Lalu mencari geometric means dari nilai fuzzy comparison ( $\left.\widetilde{r}_{i}\right)$, Tabel 3. Setelah ditemukan $\tilde{r}_{\imath}$ dilanjutkan dengan penentuan bobot relative fuzzy dari kriteria ( $\widetilde{w_{\imath}}$ ). Maka didapat bobot kriteria setelah dinormalisasi, Tabel 5.

Tabel 2. Matriks Comparison dari kriteria

\begin{tabular}{llllll}
\hline Kriteria & Waktu & Kualitas & Biaya & Kinerja Tim & Lingkungan \\
\hline Waktu & $(1,1,1)$ & $(1,1,1)$ & $(4,5,6)$ & $(6,7,8)$ & $(4,5,6)$ \\
Kualitas & $(1,1,1)$ & $(1,1,1)$ & $(4,5,6)$ & $(6,7,8)$ & $(6,7,8)$ \\
Biaya & $(1 / 6,1 / 5,1 / 4)$ & $(1 / 6,1 / 5,1 / 4)$ & $(1,1,1)$ & $(1 / 4,1 / 3,1 / 2)$ & $(2,3,4)$ \\
Kinerja Tim & $(1 / 8,1 / 7,1 / 6)$ & $(1 / 8,1 / 7,1 / 6)$ & $(2,3,4)$ & $(1,1,1)$ & $(1 / 6,1 / 5,1 / 4)$ \\
Lingkungan & $(1 / 6,1 / 5,1 / 4)$ & $(1 / 8,1 / 7,1 / 6)$ & $(1 / 4,1 / 3,1 / 2)$ & $(4,5,6)$ & $(1,1,1)$ \\
\hline
\end{tabular}


Tabel 3. Geometric means dari nilai fuzzy comparison

\begin{tabular}{llll}
\hline Kriteria & \multicolumn{3}{c}{$\widetilde{r}_{i}$} \\
\hline Waktu & 2,49 & 2,81 & 3,10 \\
Kualitas & 2,7 & 3,00 & 3,29 \\
Biaya & 0,43 & 0,53 & 0,66 \\
Kinerja Tim & 0,35 & 0,41 & 0,49 \\
Lingkungan & 0,46 & 0,54 & 0,66 \\
Total & 6,43 & 7,30 & 8,20 \\
Reverse & 0,16 & 0,14 & 0,12 \\
Inc. Order & 0,12 & 0,14 & 0,16 \\
\hline
\end{tabular}

Tabel 4. Bobot relative fuzzy dari kriteria

\begin{tabular}{lccc}
\hline Kriteria & \multicolumn{3}{c}{$\widetilde{w_{\iota}}$} \\
\hline Waktu & 0,304 & 0,385 & 0,483 \\
Kualitas & 0,330 & 0,412 & 0,511 \\
Biaya & 0,052 & 0,072 & 0,103 \\
Kinerja Tim & 0,043 & 0,057 & 0,076 \\
Lingkungan & 0,056 & 0,075 & 0,103 \\
\hline
\end{tabular}

Tabel 5. Bobot kriteria setelah dinormalisasi

\begin{tabular}{lll}
\hline Kriteria & $\mathbf{M}_{\mathbf{i}}$ & $\mathbf{N}_{\mathbf{i}}$ \\
\hline Waktu & 0,391 & 0,383 \\
Kualitas & 0,418 & 0,409 \\
Biaya & 0,075 & 0,074 \\
Kinerja Tim & 0,058 & 0,057 \\
Lingkungan & 0,078 & 0,076 \\
\hline
\end{tabular}

2. Pembobotan dan perangkingan alternatif berdasarkan kriteria.

Setelah ditemukan nilai bobot dari kriteria maka selanjutnya adalah pembobotan dan perangkingan alternatif berdasarkan nilai kriteria. Tahapan dalam pembobotan alternatif dimulai dengan penentuan matriks comparison dari alternatif, Tabel 6. Selanjutnya, pencarian nilai $\widetilde{r_{\imath}}$ dan $\widetilde{w_{\imath}}$ yang ditampikan pada Tabel 7. Dalam Tabel 8 dan Tabel 9 ditampilkan nilai pembobotan setelah dilakukan normalisasi. Hasil dari pembobotan dan skor untuk masing-masing alternatif ditampilkan pada Tabel 10.

Tabel 6. Matriks comparison dari alternatif

\begin{tabular}{llll}
\hline Alternatif & A1 & A2 & A3 \\
\hline A1 & $(1,1,1)$ & $(1 / 6,1 / 5,1 / 4)$ & $(1 / 9,1 / 9,1 / 9)$ \\
A2 & $(4,5,6)$ & $(1,1,1)$ & $(1 / 4,1 / 3,1 / 2)$ \\
A3 & $(9,9,9)$ & $(2,3,4)$ & $(1,1,1)$ \\
\hline
\end{tabular}

Tabel 7. Geometric means dan fuzzy weights

\begin{tabular}{lcccccc}
\hline Alternatif & \multicolumn{3}{c}{$\widetilde{r}_{l}$} & & & $\widetilde{w}_{\boldsymbol{l}}$ \\
\hline A1 & 0,265 & 0,281 & 0,303 & 0,052 & 0,063 & 0,078 \\
A2 & 1 & 1,186 & 1,442 & 0,198 & 0,265 & 0,371 \\
A3 & 2,621 & 3 & 3,302 & 0,519 & 0,672 & 0,850
\end{tabular}




\begin{tabular}{lcccc}
\hline Alternatif & \multicolumn{3}{c}{$\widetilde{r}_{l}$} & $\widetilde{w}_{\iota}$ \\
\hline Total & 3,885 & 4,467 & 5,047 & \\
Reverse & 0,257 & 0,224 & 0,198 & \\
Increasing Order & 0,198 & 0,224 & 0,257 & \\
\hline
\end{tabular}

Tabel 8. Averaged dan normalisasi relative weights dari alternatif

\begin{tabular}{lll}
\hline Alternatif & $\mathrm{M}_{\mathrm{i}}$ & $\mathrm{N}_{\mathrm{i}}$ \\
\hline A1 & 0,064 & 0,063 \\
A2 & 0,278 & 0,270 \\
A3 & 0,680 & 0,665 \\
\hline
\end{tabular}

Tabel 9. Normalisasi dari non-fuzzy

\begin{tabular}{llllll}
\hline Alteratif & Waktu & Kualitas & Biaya & Kinerja Tim & Lingkungan \\
\hline A1 & 0,063 & 0,425 & 0,629 & 0,149 & 0,629 \\
A2 & 0,270 & 0,425 & 0,107 & 0,784 & 0,107 \\
A3 & 0,666 & 0,151 & 0,263 & 0,067 & 0,263 \\
\hline
\end{tabular}

Tabel 10. Hasil dan skor alternatif berdasarkan kriteria

\begin{tabular}{lllll}
\hline Kriteria & & \multicolumn{3}{c}{ Skor Alternatif } \\
\hline & Bobot & $\mathbf{A 1}$ & $\mathbf{A 2}$ & $\mathbf{A 3}$ \\
\hline Waktu & 0,383 & 0,063 & 0,270 & 0,666 \\
Kualitas & 0,409 & 0,425 & 0,425 & 0,151 \\
Biaya & 0,074 & 0,629 & 0,107 & 0,263 \\
Kinerja Tim & 0,057 & 0,149 & 0,784 & 0,067 \\
Lingkungan & 0,076 & 0,629 & 0,107 & 0,263 \\
Total & & $\mathbf{0 , 3 0 1}$ & $\mathbf{0 , 3 3 7}$ & $\mathbf{0 , 3 6 1}$ \\
\hline
\end{tabular}

Berdasarkan tahapan diatas, maka proyek potensial yang direkomendasikan adalah subbidang perpipaan berdasarkan nilai skor tertinggi, dengan total skor 0,361. Maka perangkingan proyek berdasarkan jumlah skor adalah sub-bidang perpipaan, sub-bidang pengolahan air limbah dan sub-bidang irigasi.

\section{SIMPULAN}

Perangkingan proyek berdasarkan evaluasi proyek sebelumnya dapat dilakukan dengan pendekatan Fuzzy AHP. Kriteria yang digunakan adalah waktu, kualitas, biaya, kinerja tim dan lingkungan, terdapat tiga alternatif sub-bidang irigasi, pengelolaan limbah dan perpipaan. Skor tertinggi dari antara ketiga sub-bidang adalah sub-bidang perpipaan dengan total skor 0,360 . Maka proyek paling potensial diantara ketiga alternatif yang direkomendasikan adalah sub-bidang perpipaan. Metode yang digunakan adalah Fuzzy AHP, pada penelitian selanjutnya dengan menggunakan metode Multi Criteria Decision Analysis (MCDA) yang lain. 


\section{REFERENSI}

[1] Ng, S. T. dan Tang, Z. 2010. Labour-Intensive Construction Sub-Contractors: Their Critical Success Factors. International Journal of Project Management. Vol. 28(7): 732-740.

[2] Safa, M., Shahi, A., Haas C. T., dan Hipel, K. W. 2014. Automation In Construction Supplier Selection Process In an Integrated Construction Materials Management Model. Automation in Construction. Vol. 48: 64-73.

[3] Alzahrani, J. I., Emsley, M. W. 2013. The Impact Of Contractor's Attributes On Construction Project Success: A post construction evaluation. JPMA. Vol. 31(2): 313-322.

[4] Akadiri, P. O., Olomolaiye, P. O., dan Chinyio, E.A. 2013. Automation In Construction Multi-Criteria Evaluation Model for The Selection of Sustainable Materials for Building Projects. Automation in Construction. Vol. 30: 113-125.

[5] Ruiz, M. C., Romero, E., Pérez, M. A., dan Fernández, I. 2012. Automation In Construction Development and Application of a Multi-Criteria Spatial Decision Support System for Planning Sustainable Industrial Areas In Northern Spain. Automation in Construction. Vol. 22: 320-333.

[6] Nguyen, H., Zawiah, S., Nukman, Y., dan Aoyama, H. 2014. Expert Systems With Applications a Hybrid Approach for Fuzzy Multi-Attribute Decision Making In Machine Tool Selection With Consideration of The Interactions of Attributes. Expert Systems With Applications. Vol. 41, no. 6: 3078-3090.

[7] Nassar, K. dan Hosny, O. 2013. Automation In Construction Fuzzy Clustering Validity for Contractor Performance Evaluation: Application To UAE Contractors. Automation in Construction. Vol. 31: 158-168.

[8] Ergu, D., Kou, G., dan Shi, Y. 2014. Computers \& Operations Research Analytic Network Process In Risk Assessment and Decision Analysis. Computers and Operation Research. Vol. 42: 58-74.

[9] Behzadian, M., Otaghsara, S. K., Yazdani, M., dan Ignatius, J. 2012. Expert Systems With Applications a State-Of The-Art Survey Of TOPSIS Applications. Expert Systems With Applications. Vol. 39, no. 17: 13051-13069.

[10] Igoulalene, I., Benyoucef, L., dan Kumar, M. 2015. Expert Systems With Applications Novel Fuzzy Hybrid Multi-Criteria Group Decision Making Approaches for The Strategic Supplier Selection Problem. Expert Systems With Applications. Vol. 42(7): 3342-3356.

[11] Aminbakhsh, S., Gunduz, M., dan Sonmez, R. 2013. Safety Risk Assessment using Analytic Hierarchy Process (AHP) During Planning And Budgeting of Construction Projects. Journal of Safety Research. Vol. 46: 99-105.

[12] Rezaei, J., Fahim, P. B. M., dan Tavasszy, L. 2014. Expert Systems With Applications Supplier Selection In The Airline Retail Industry using a Funnel Methodology: Conjunctive Screening Method And Fuzzy AHP. Expert Systems With Applications. Vol. 41(18): 8165-8179.

[13] Kabak, M., Köse, E., dan Burmao, S. 2014. A Fuzzy Multi-Criteria Decision Making Approach to Assess Building Energy Performance. Automation in Construction . Vol. 72: 382-389.

[14] Shaw, K., Shankar, R., Yadav, S. S. dan Thakur, L. S. 2012. Expert Systems With Applications Supplier Selection using Fuzzy AHP and Fuzzy Multi-Objective 
Linear Programming for Developing Low Carbon Supply Chain. Expert Systems With Applications. Vol. 39(9): 8182-8192.

[15] Pan, N. 2008. Automation In Construction Fuzzy AHP Approach for Selecting The Suitable Bridge Construction Method. Automation in Construction. Vol. 17: 958-965. 
